\title{
Protein Phosphatase Magnesium Dependent 1A Governs the Wound Healing-Inflammation-Angiogenesis Cross Talk on Injury
}

Zeev Dvashi, ${ }^{*}$ Hadas Sar Shalom, ${ }^{*}$ Meytal Shohat, ${ }^{*}$ Daniella Ben-Meir, ${ }^{*}$ Shiran Ferber, ${ }^{\dagger}$ Ronit Satchi-Fainaro, Ruth Ashery-Padan, ${ }^{\ddagger}$ Mordechai Rosner, ${ }^{\S}$ Arieh S. Solomon, ${ }^{\S}$ and Sara Lavi*

From the Department of Cell Research and Immunology, * The George S. Wise Faculty of Life Sciences, the Departments of Physiology and Pharmacology, ${ }^{\dagger}$ and Molecular Human Genetics and Biochemistry, ${ }^{\ddagger}$ Sackler Faculty of Medicine, and the Goldschleger Eye Research Institute, ${ }^{\S}$ Sheba Medical Center, Tel Hashomer, Tel-Aviv University, Ramat-Aviv, Tel-Aviv, Israel

Accepted for publication

July 18, 2014.

Address correspondence to Sara Lavi, Ph.D., Department of Cell Research and Immunology, The George S. Wise Faculty of Life Sciences, Tel Aviv University. E-mail: saralav@tauex.tau.ac.il.
Protein phosphatase magnesium dependent $1 \mathrm{~A}$ (PPM1A) has been implicated in fibrosis and skin wounding. We generated PPM1A knockout mice to study the role of PPM1A in the wound healing-inflammation-angiogenesis cross talk. The role of PPM1A in these processes was studied using the ocular alkali burn model system. In the injured cornea the absence of PPM1A led to enhanced inflammatory response, stromal keratocyte transactivation, fibrosis, increased p38 mitogen-activated protein kinase phosphorylation, elevated expression of transforming growth factor- $\beta$-related genes (including Acta2, TGF- $\beta$, Col1, MMP9, and VEGF) and subsequently to neovascularization. Augmented angiogenesis in the absence of PPM1A is a general process occurring in vivo in PPM1A knockout mice upon subcutaneous Matrigel injection and ex vivo in aortic ring Matrigel cultures. Using primary keratocyte cultures and various experimental approaches, we found that phospho-p38 is a favored PPM1A substrate and that by its dephosphorylation PPM1A participates in the regulation of the transforming growth factor- $\beta$ signaling cascade, the hallmark of inflammation and the angiogenic process. On the whole, the studies presented here position PPM1A as a new player in the wound healing-inflammation-angiogenesis axis in mouse, reveal its crucial role in homeostasis on injury, and highlight its potential as a therapeutic mediator in pathologic conditions, such as inflammation and angiogenesis disorders, including cancer. (Am J Pathol 2014, 184: 2936-2950; http://dx.doi.org/10.1016/j.ajpath.2014.07.022)
Angiogenesis, the formation of new blood vessels, is an important natural process in health and disease. ${ }^{1,2}$ In the healthy body, it occurs primarily in embryonic development, during wound healing, and in response to ovulation. However, under pathologic conditions, angiogenesis is implicated in many diseases, affecting $>1$ billion people worldwide. This disease includes all cancers, cardiovascular diseases, blindness, arthritis, and multiple additional major health conditions, affecting children and adults all over the globe. ${ }^{3-5}$

Angiogenesis is controlled through on-and-off switches that induce halt or inhibit the angiogenic process. When this balance is tilted in favor of blood vessel growth, this results in pathologic angiogenesis. ${ }^{6}$ Multiple endogenous positive regulators of angiogenesis have been described, including growth factors, matrix metalloproteinases (MMPs), cytokines, and integrins. ${ }^{7}$ Substantial evidence indicates that upregulation of vascular endothelial growth factor (VEGF) and its receptors plays a central role in angiogenesis. ${ }^{3,8}$ Angiogenesis is also important in inflammation, and VEGF is a major player in the cross talk between these processes. ${ }^{9}$ VEGF promotes several steps of angiogenesis, including endothelial

Supported by the Linda Tallen and David Paul Kane Educational and Research Foundation (S.L.), the medical research fund of the Weichselbaum family (S.L.), the Israel Ministry of Health (S.L.), and the Israel Cancer Association (S.L.).

This work is a partial fulfillment of the requirements toward the Ph.D. degree of Z.D. at the Faculty of Life Sciences, Tel-Aviv University.

Disclosures: None declared. 
cell proliferation, migration, and capillary tube formation, and serves as a target for treatment of unrestrained angiogenesis. ${ }^{10}$

Angiogenesis is initiated by the release of proangiogenic factors that attract inflammatory and endothelial cells and promote their proliferation. During their migration, inflammatory cells also secrete molecules that intensify the angiogenic stimuli. ${ }^{11}$ The endothelial cells that form the blood vessels then respond by differentiation and secretion of MMPs, which facilitate the digestion of the blood-vessel walls and migration toward the site of the angiogenic stimuli. After proliferation and further migration, the endothelial cells form capillary tubes and finally new blood vessels appear. ${ }^{12,13}$

Corneal neovascularization is a well-established in vivo model system for the study of angiogenesis because the visibility, accessibility, and avascularity of the cornea are highly advantageous in assessing neovascularization. ${ }^{14}$ The newly formed vessels, penetrating from the limbus into the corneal stroma after stimulation by angiogenesis-inducing agents, are all new, are readily visible, and can be quantified. In corneal neovascularization, increased levels of VEGF receptor, VEGF mRNA, and protein have been reported. ${ }^{15,16}$

We present a new player in the inflammationangiogenesis cross talk, namely, protein phosphatase magnesium dependent 1A (PPM1A). Using PPM1A knockout (KO) mice prepared in our laboratory, we report here for the first time that PPM1A is a prominent negative regulator of angiogenesis and that in its absence the balance is tilted toward enhanced angiogenesis. PPM1A belongs to the highly conserved metal-dependent serine threonine protein phosphatase family PPM $1 .{ }^{17}$ These enzymes are monomeric phosphatases that depend on divalent ions, are highly conserved, and are expressed in various organisms, ranging from yeast to higher eukaryotes. ${ }^{18,19}$ At least 16 different PPM1 genes have been identified in mammalian cells. ${ }^{17}$ PPM1A is involved in the regulation of key cellular functions via several signaling pathways, such as $\mathrm{p} 38-$ mitogenactivated protein kinase (MAPK), c-Jun $\mathrm{N}$-terminal kinase (JNK), transforming growth factor- $\beta$ (TGF- $\beta$ ), and Wnt. ${ }^{20-28}$ Recently, PPM1A was found to be engaged in fibrosis and skin wounding in vivo. ${ }^{27,29,30}$

We used PPM1A KO mice lacking phosphatase in all their tissues to study its role after injury using the corneal alkaline burn model. The acute corneal injury sequence after alkali burn includes the following: i) inflammation and degradation of the epithelial basement membrane matrix and stroma; ii) influx of inflammatory cells, including macrophages and/or polymorphonuclear leukocytes; iii) activation of corneal keratocytes and formation and transdifferentiation of myofibroblasts; iv) tissue contraction with increased extracellular matrix protein expression; and v) tissue scarring. ${ }^{31-33}$ Abnormal corneal healing causes the appearance of new blood vessels in the avascular transparent cornea, leading to pathologic consequences. ${ }^{34}$

We found that PPM1A plays a key role in the wound healing process in mouse. The lack of PPM1A in the injured cornea led to aberrant wound healing, inflammation, and neovascularization. Moreover, our studies found that PPM1A is a general negative regulator of angiogenesis.

The formation of new blood vessels was preceded by up-regulated TGF- $\beta$ signaling, increased expression of proinflammatory and proangiogenic factors, and uncontrolled VEGF expression. Using corneal primary fibroblasts, we found that in the absence of PPM1A, the overactivated TGF- $\beta$ signaling led to increased production of proinflammatory and proangiogenic factors, such as VEGF, MMP-9, and TGF- $\beta$, and to enhanced keratocyte activation. Finally, we found that PPM1A participates in the termination of the TGF- $\beta$ noncanonical signaling through the dephosphorylation of p38 and that in its absence TGF- $\beta$ signaling is deregulated.

Unraveling the role of PPM1A in inflammation and angiogenesis might lead to the development of novel diagnostic and therapeutic approaches to prevent angiogenesis in ocular diseases, such as age-related macular degeneration, as well as during cancer progression.

\section{Materials and Methods}

Animal care and all experiments were conducted in accordance with institutional guidelines and were approved by the Institutional Animal Care and Use Committee, The George S. Wise Faculty of Life Sciences, Tel-Aviv University (permit L-11-010).

\section{Generation of Conditional PPM1A K0 Mice}

We used the two LoxP-two Frt approach using the pPNT Frt Neo LoxP vector. ${ }^{35}$ The neomycin-resistant cassette was flanked by two genomic sequences of the PPMIA gene (NCBI-NT-039551) [wild-type (WT) allele] (Figure 1A). The left arm $\left(5^{\prime}\right)$ contained $3.2 \mathrm{~Kb}$ derived from intron 1 (bp 31205434-31208643), and the right arm consisted of 4.9 $\mathrm{Kb}$ from the end of intron 1 to intron 3 (bp 31208685 to 31213596). Exon 2 was flanked by two LoxP sites (targeting vector) (Figure 1A). The linearized vector was electroporated into embryonic stem (ES) cells derived from SV129 mice. ES cells that underwent correct homologous recombination were aggregated into ICR blastocysts and implanted into pseudopregnant foster mothers (ICR). Chimeric mice were tested for incorporation of the ES cells by the color of their fur and eyes. Chimeric male mice were crossed with C57 black females to generate heterozygous PPM1A $\mathrm{A}^{\text {Flox/ }+}$ mice (recombinant allele) (Figure 1A). The neomycin-resistant cassette was removed using the Flp-Frt system. On mating with phosphoglycerate kinase (PGK)-1-Cre mice, ${ }^{36}$ in which the Cre recombinase is under the $\mathrm{PGK}$ promoter, the complete $P P M 1 A$ $\mathrm{KO}$ mice were generated (PPM1A $\mathrm{KO}$ and $\mathrm{KO}$ allele) (Figure 1A). The mice were backcrossed to the $\mathrm{C} 57$ black mice for five generations and were $96.875 \%$ C57 black. For all experiments, we used WT and PPMIA KO mice littermates of heterozygote mice. 
A
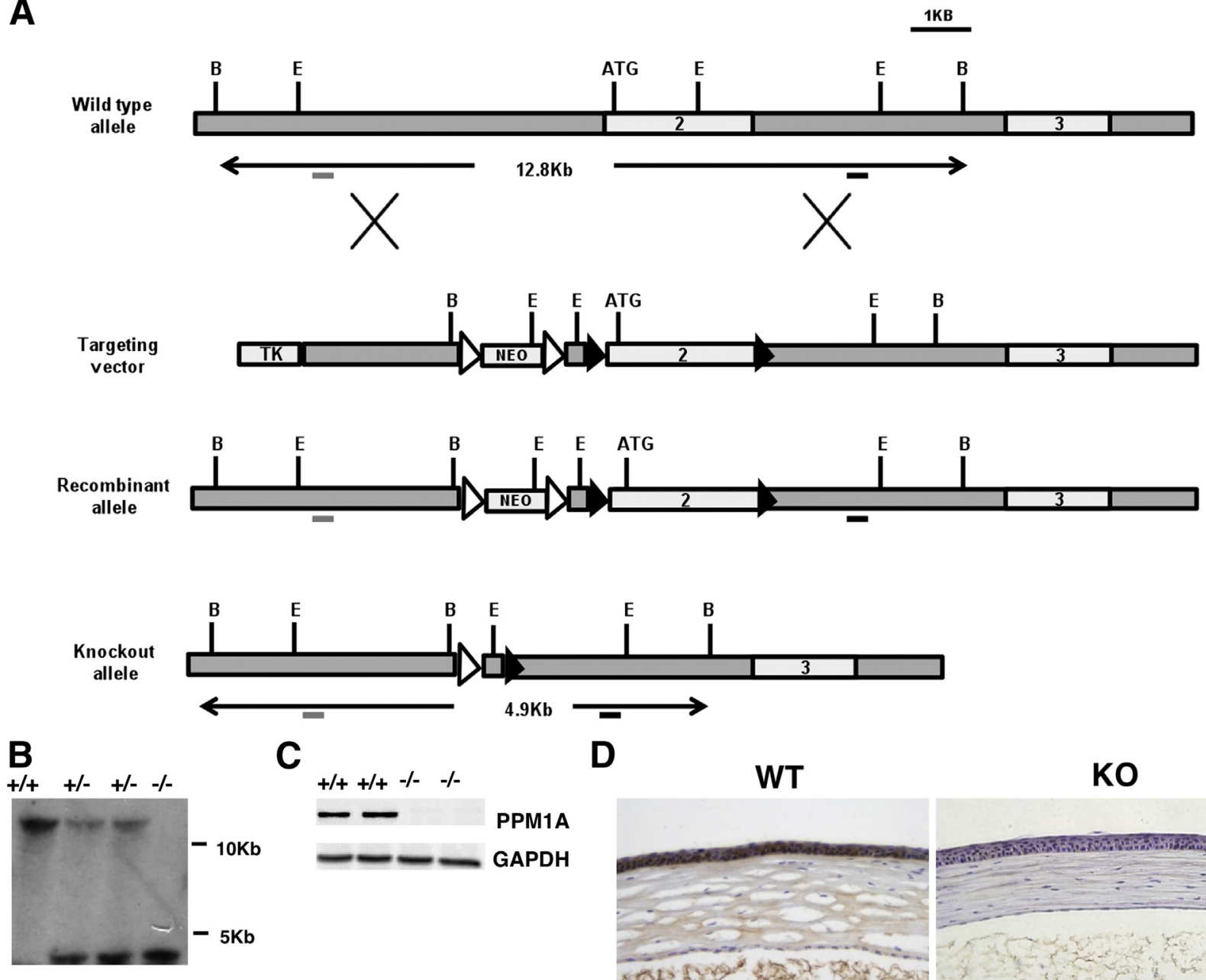

Figure 1 The PPM1A knockout (KO) mice. A: Schematic maps of the wild-type (WT) PPM1A allele, the targeting vector, and the recombinant and K0 alleles. B: Southern blot analysis of genomic DNA from WT, heterozygous, and KO mice. B: BamHI-digested DNA was hybridized with the $3^{\prime}$ probe that depicts exon 2 deletion. The WT and $\mathrm{KO}$ alleles are $12.8 \mathrm{~Kb}$ and $4.9 \mathrm{~Kb}$ in length, respectively. C: Western blot analysis of PPM1A from WT and K0 mice. Protein extracts from mice tails were challenged with antibodies against PPM1A and glyceraldehyde-3-phosphate dehydrogenase (GAPDH) (the loading control). D: Immunohistochemistry of PPM1A in age-matched WT and K0 mice corneas (week 14) and isotype control stained with rabbit IgG. LoxP site (black triangle), flippase recognition target site (white triangle), exons (light gray box), introns (dark gray box), region of homologous recombination (X), $3^{\prime}$ probe (black bar), and $5^{\prime}$ probe (gray bar) are shown. Scale bar $=100 \mu \mathrm{m}$. E, EcoRV restriction sites; NEO, neomycin-resistant cassette; TK, thymidine kinase cassette.

\section{Southern Blot Analysis}

Digested DNA $(10 \mu \mathrm{g})$ was separated by electrophoresis using $0.7 \%$ agarose gel. The gels were washed in $0.25 \mathrm{~N}$ HCL, denatured, and neutralized. The gels were then transferred overnight in $20 \times$ standard saline citrate to Hybond $^{+}$ membranes (GE Healthcare Bio-Sciences, Pittsburgh, PA) and washed in $2 \times$ standard saline citrate. Hybridization was performed using ${ }^{32} \mathrm{P}$-labeled probes (GE Healthcare BioSciences). After washing, the membranes were exposed overnight to a high-sensitivity MS film (Kodak, Rochester, $\mathrm{NY})$ at $-80^{\circ} \mathrm{C}$.

\section{Histology and IHC}

Paraffin-embedded sections $(9 \mu \mathrm{m})$ were stained with hematoxylin and eosin ${ }^{37}$ and underwent antigen retrieval by boiling (10 mmol/L citrate buffer for 20 minutes), rinsed in phosphate-buffered saline (PBS), incubated for 1 hour with $0.2 \%$ Tween and gelatin in PBS, washed with PBS, blocked with $2 \%$ normal goat serum in $1 \%$ bovine serum albumin and $0.1 \%$ Triton X-100 for 30 minutes, and incubated overnight with primary antibodies diluted in PBS. Antibodies used included mouse monoclonal anti- $\alpha$-smooth muscle actin $(\alpha-S M A ;$ Sigma-Aldrich, St. Louis, MO), rat monoclonal anti-Mac-3 (BD Pharmingen, San Jose, CA), rat monoclonal anti-CD31 (Abcam, Cambridge, UK), rabbit polyclonal antiVEGF (Abcam), and mouse monoclonal anti-proliferating cell nuclear antigen (Santa Cruz Biotechnology, Santa Cruz, CA). After primary antibody reaction, the slides were washed twice with $2 \%$ bovine serum albumin-PBS and incubated for 120 minutes in the dark with secondary antibodies labeled with Alexa Fluor 488/555 (Invitrogen, Carlsbad, CA). The slides were then washed with PBS for 10 minutes, and nuclei 
were stained by incubation with DAPI for 30 minutes. Finally, the slides were washed three times with PBS, glued with mounting medium (Biomeda, Foster City, CA), and photographed. The photographs were deconvoluted and processed using a Leica laser confocal microscope (Leica Microsystems, Buffalo, NY).

\section{Protein Analysis}

Cells were lyzed in $50 \mathrm{mmol} / \mathrm{L}$ Tris, $150 \mathrm{mmol} / \mathrm{L} \mathrm{NaCl}$, and 5 $\mathrm{mmol} / \mathrm{L}$ EGTA $(\mathrm{pH} 7.5)$ and supplemented with complete protease inhibitors, $0.75 \% \mathrm{NP}-40,2 \mathrm{mmol} / \mathrm{L} \mathrm{Na} \mathrm{NO}_{4}, 50$ $\mathrm{mmol} / \mathrm{L} \mathrm{NaF}$, and $10 \mathrm{mmol} / \mathrm{L} \mathrm{NaPPi}$. Proteins were separated by SDS-PAGE, transferred to nitrocellulose membranes, and immunoblotted with the relevant primary antibodies: mouse monoclonal anti-PPM1 A antibodies $\left(9 \mathrm{~F} 4^{38}\right)$, monoclonal antiphospho-p38 (Thr180/Tyr182) antibodies (Sigma), rabbit polyclonal anti-p38 antibodies (Sigma), rabbit monoclonal anti-phospho-Smad3 (Ser423/425) antibodies (Cell Signaling, Beverly, MA), rabbit polyclonal anti-Smad3 antibodies (Cell Signaling), and monoclonal anti-glyceraldehyde-3-phosphate dehydrogenase (GAPDH) antibodies (Millipore, Billerica, MA). After reaction with the appropriate secondary peroxidaseconjugated IgG antibodies (Jackson Laboratories, Bar Harbor, ME), the blots were subjected to enhanced chemiluminescence (Pierce Biotechnology, Inc., Rockford, IL) and monitored using the Molecular Imager ChemiDoc XRS System (Bio-Rad Laboratories, Philadelphia, PA). Quantification was performed using Quantity One 1-dimensional analysis software, with GAPDH as a loading control.

\section{Alkali Burn in Mouse Eyes}

WT and KO mice 14 to 16 weeks old underwent general (xylazine/ketamine $10 \mathrm{mg} / \mathrm{kg}$ weight) and topical (Localin) anesthesia followed by alkaline burn. Whatman paper $(2 \times 2 \mathrm{~mm})$ presoaked in $0.5 \mathrm{~N} \mathrm{NaOH}$ was applied onto the center of the right eye for 30 seconds followed by excessive wash with PBS for 1 minute to reach $\mathrm{pH} 7$. The mice were observed until fully awakened and then returned to their natural habitat. Throughout the experiment, the mice were monitored daily, and mice with obvious bacterial infection were excluded from the study. The mice were morphologically examined at days 2,7 , and 22 after wounding. At the indicated times, mice were sacrificed and their eyes enucleated and processed for histology and immunohistochemistry (IHC), as well as for corneal RNA extraction. All the mice used in the corneal alkaline burn experiments were from the same sets.

\section{Aortic Ring Assay}

The assay was performed by using isolated descending thoracic aorta segments $1 \mathrm{~mm}$ in length, embedded in BD Matrigel (BD Biosciences, San Jose, CA) supplemented with $20 \mathrm{U} / \mathrm{mL}$ of heparin with or without the p38 inhibitor
SB203580 (10 $\mu \mathrm{mol} / \mathrm{L}$, Millipore). The aortic rings were then cultured in endothelial growth medium at $37^{\circ} \mathrm{C}$ for 8 days. ${ }^{39}$

\section{Matrigel Plug Assay}

Mice were injected subcutaneously in the abdomen with 0.7 $\mathrm{mL}$ of BD Matrigel Matrix Growth Factor Reduced containing $30 \mathrm{ng}$ of VEGF-C (2179-VC; R\&D Systems, Minneapolis, MN). Seven days after implantation, the Matrigel implants were harvested and photographed, and hemoglobin content was measured with Drabkin reagent (Ricca Chemical, Arlington, TX). ${ }^{40}$

\section{RNA Extraction and cDNA Synthesis}

Total RNA was prepared from adult mice corneas (14 to 16 weeks) or from primary keratocytes using the EZ-RNA kit (Biological Industries, Kibbutz Beit-Haemek, Israel). RNA was quantified by the NanoDrop ND-1000 UV-Vis Spectrophotometer (Thermo-Scientific, Wilmington, DE) at 260 $\mathrm{nm}$. RNA $(1 \mu \mathrm{g})$ was used for cDNA synthesis using the Thermo Verso real-time quantitative PCR (qPCR) kit (Thermo Scientific, Pittsburgh, PA).

\section{qPCR}

qPCR was performed using the KAPA SYBR FAST qPCR Kit (Kapo Biosystems, Wilmington, MA) and a Corbett Research RG-6000 real-time detection system (Corbett Research, New South Wales, Australia). Assays for each sample and each primer set were performed in triplicate, using $1.5 \mu \mathrm{L}$ of diluted cDNA and $0.3 \mu \mathrm{mol} / \mathrm{L}$ primers in a total reaction volume of $10 \mu \mathrm{L}$. The primer list is presented in Table 1. Cycling conditions were as follows: activation for 3 minutes at $95^{\circ} \mathrm{C}$, followed by 35 cycles of denaturation for 3 seconds at $95^{\circ} \mathrm{C}$, annealing and extension 30 seconds at $60^{\circ} \mathrm{C}$, and a melting curve program at $72^{\circ} \mathrm{C}$ to $95^{\circ} \mathrm{C}$. In the $\mathrm{qPCR}$ reaction, the threshold was set at the start of the log-linear phase and kept constant for all the experiments using the same set of primers. The relative gene expression in different samples was calculated by extrapolation of the cycle threshold to a standard curve of the gene of interest and of GAPDH or HPRT1 (normalizing genes) separately. Standard curves were performed in each experiment. All experiments were performed in triplicate.

\section{Primary Corneal Keratocyte Cultures}

Mouse ocular fibroblasts were obtained from the eyes of postnatal day 1 mice. Mice eyeballs were encapsulated, stroma isolated, and explanted in collagen-coated 6-well culture dishes. Corneal fibroblasts were initially grown in MEM alpha supplemented with $10 \%$ fetal bovine serum (FBS) that was replaced with fresh medium every 2 to 3 days. At the first passage the cells were seeded and grown in Dulbecco's modified Eagle's medium with 10\% FBS. Note 
Table 1 List of Primers Used in the Study

\begin{tabular}{|c|c|c|c|}
\hline Primer name & Sequence & Bases & Application \\
\hline Left 2 reverse (short) & 5'-GGATCACTGTCCCTGTTTGAC-3' & 21 & Generating of $5^{\prime}$ probe for Southern blot \\
\hline Left forward & 5'-GCAGTGCCAGTTAAGCAGTG-3' & 20 & Generating of $5^{\prime}$ probe for Southern blot \\
\hline Right reverse1 short & $5^{\prime}-$ CGTAGTACAAACCAAAACCA-3' & 20 & Generating of $3^{\prime}$ probe for Southern blot \\
\hline Right forward & 5'-ATGCATTTAAGTATTTGGAG-3' & 20 & Generating of $3^{\prime}$ probe for Southern blot \\
\hline GAPDH forward & 5'-TGGCCTCCAAGGAGTAAGAA-3' & 20 & Real-time PCR \\
\hline GAPDH reverse & 5'-GGAAATTGTGAGGGAGATGC-3' & 20 & Real-time PCR \\
\hline TGF- $\beta$ forward & $5^{\prime}-$ TGGAGCAACATGTGGAACTC-3' & 20 & Real-time PCR \\
\hline TGF- $\beta$ reverse & $5^{\prime}-\mathrm{CGTCAAAAGACAGCCACTCA-3^{ \prime }}$ & 20 & Real-time PCR \\
\hline VEGF forward & $5^{\prime}$-CAAGATCCGCAGACGTGTAA-3' & 20 & Real-time PCR \\
\hline VEGF reverse & 5'-GCTTGTCACATCTGCAAGTACG-3' & 22 & Real-time PCR \\
\hline MMP-9 forward & $5^{\prime}$-AGACGACATAGACGGCATCC-3' & 20 & Real-time PCR \\
\hline MMP-9 reverse & 5'-GTGGTTCAGTTGTGGTGGTG-3' & 20 & Real-time PCR \\
\hline
\end{tabular}

GAPDH, glyceraldehyde-3-phosphate dehydrogenase; HPRT1, hypoxanthine phosphoribosyltransferase-1; MMP-9, matrix metalloproteinase-9; PCR, polymerase chain reaction; PPM1A, protein phosphatase magnesium dependent $1 \mathrm{~A}$; VEGF, vascular endothelial growth factor.

that growth of the primary cultures in FBS, which contains residual levels of TGF- $\beta$, leads to partial differentiation of the corneal keratocytes to myofibroblasts. Fluorescenceactivated cell sorting analysis of the primary keratocytes revealed homogenous cultures devoid of monocytes and endothelial cells (Supplemental Figure S1).

\section{Collagen Contraction}

Corneal fibroblasts were resuspended at a concentration of $1.8 \times 10^{5}$ cells $/ \mathrm{mL}$ and preincubated with the $10 \mu \mathrm{mol} / \mathrm{L}$ p38 inhibitor SB203580 for 30 minutes or left untreated. Collagen was then added to the cells at a concentration of
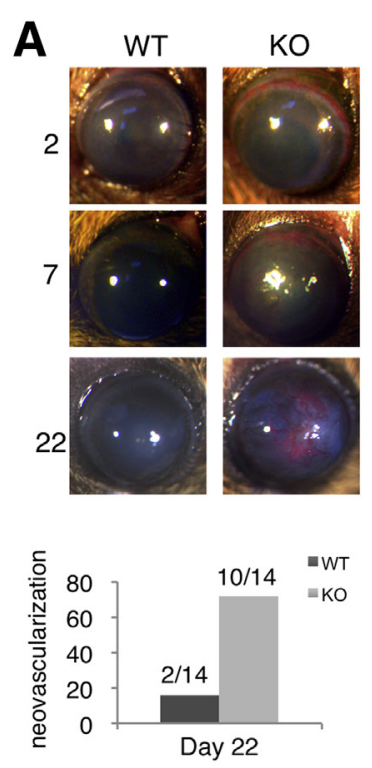

B

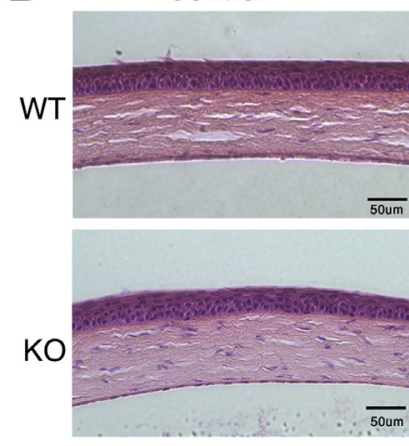

C

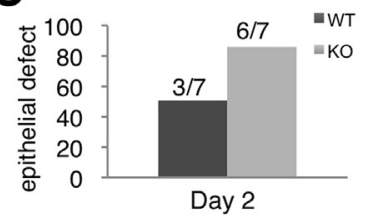

Day 2

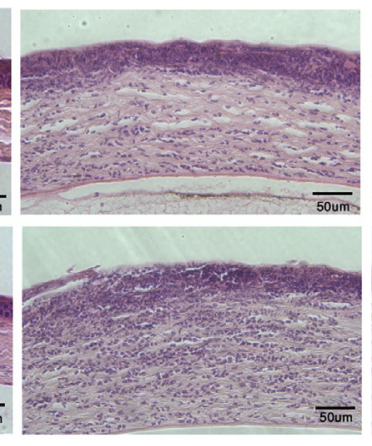

D

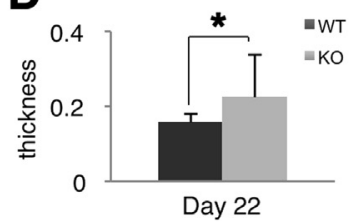

Day 22

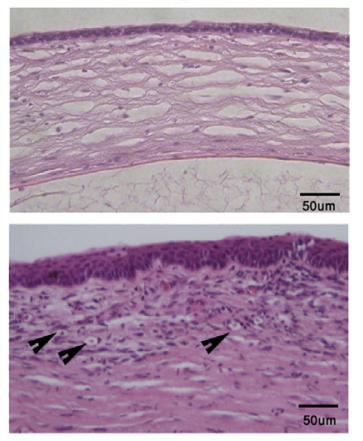

E

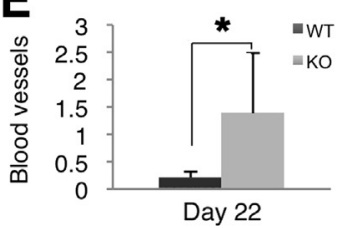

Figure 2 Neovascularization in PPM1A knockout (K0) mice on alkali burn. Age-matched (14 to 16 weeks) wild-type (WT) and K0 male mice underwent alkali burn. A: Mouse eyes (2, 7, and 22 days after injury) were photographed, and neovascularization was detected in K0 eyes at days 7 and 22 . Percentage of eyes with a positive morphologic evidence of neovascularization in the cornea ( $n=14$ for each group) (bottom). B: Histologic assessment of control and burnt corneas from WT and KO mice. Control and treated mice at day 2 and 22 days after injury were sacrificed, isolated eyes were fixed and embedded in paraffin, and sections stained with hematoxylin and eosin. C: The percentage of mice with epithelial defect 2 days after injury as determined by the appearance of incomplete epithelial layer in the central area of the cornea. D: Assessment of corneal edema. The thickness (in millimeters) of each stroma was measured from the epithelial to the endothelial layer at six different areas in the center of the cornea, using Celr $D$ software (Olympus, Southend-on-Sea, UK). E: Number of blood vessels per square millimeter in the wounded center of the stroma. Bars are means \pm SD ( $n=10$ for each group). All statistical analyses were performed with Student's $t$-test (two-tailed distribution, equal variance). ${ }^{*} P<0.05$. 

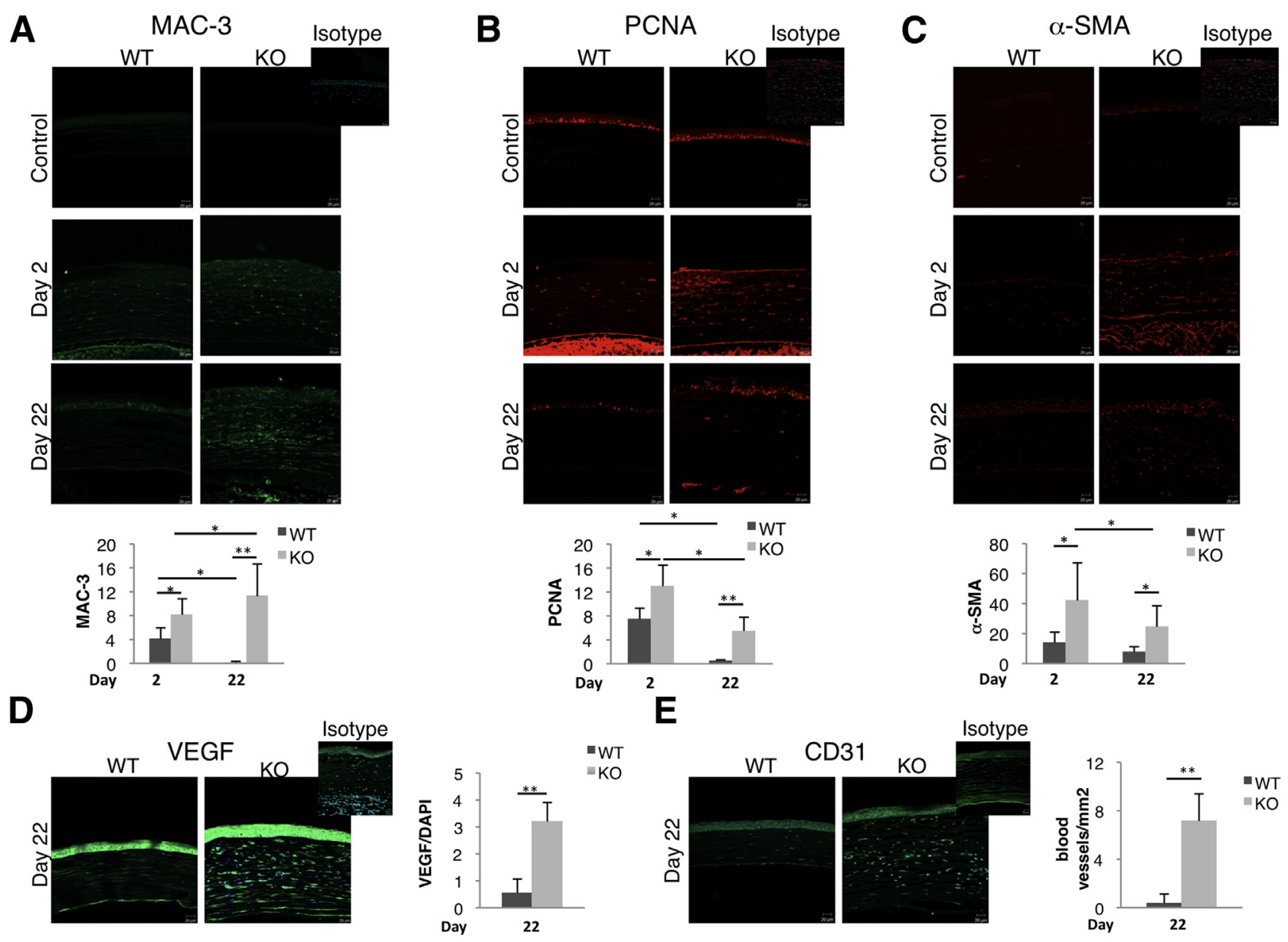

$\mathbf{F}$
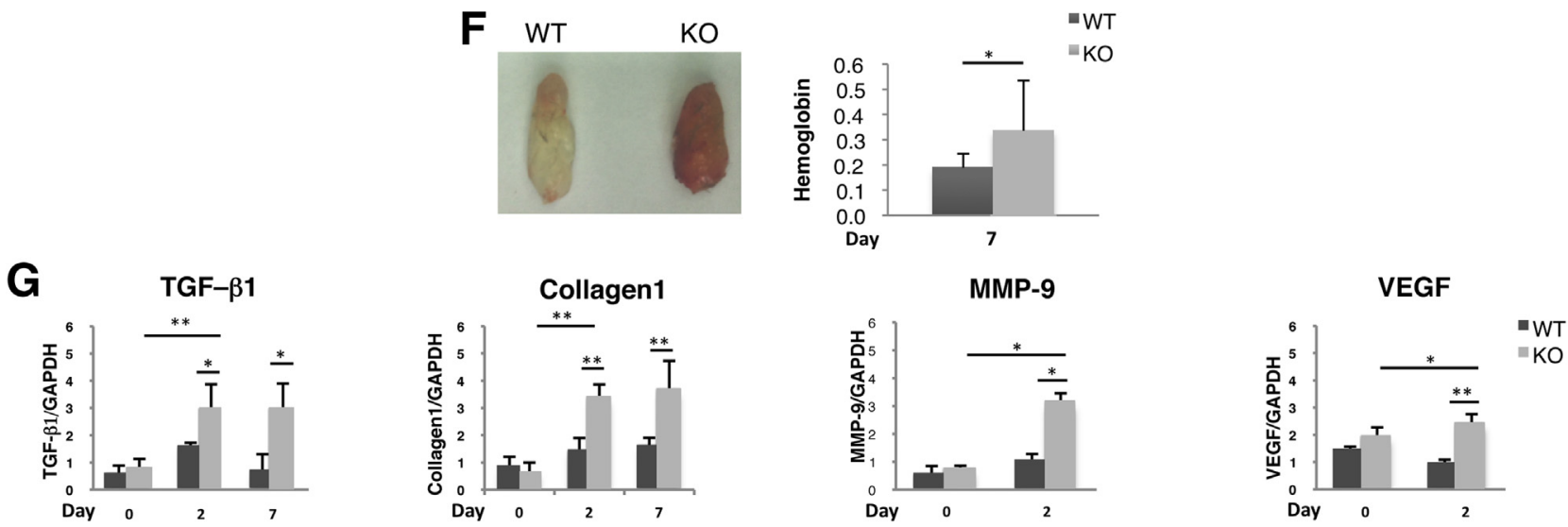

Figure 3 Enhanced inflammation, fibrosis, and angiogenesis in corneas of PPM1A knockout (K0) mice. Immunohistochemistry of corneal paraffin sections from control and injured mice at days 2 and 22 after alkali burn. Sections were stained with the indicated antibodies. Isotype control staining for each antibody is presented as the control. Histograms represent quantification per square millimeter. A: Monocytes and macrophages labeled with Mac-3. B: Stromal keratocytes and infiltrating cells stained with proliferating cell nuclear antigen (PCNA). C: Keratocytes stained with $\alpha$-smooth muscle actin $(\alpha-S M A)$. D: Endothelial cells and stroma stained with vascular endothelial growth factor (VEGF). E: Endothelial cells stained with CD31 (number of blood vessels per square millimeter; $n=10$ for each group). F: Data are expressed as the means \pm SD. F: PPM1A regulates angiogenesis in vivo. G: BD Matrigel Matrix Growth Factor Reduced $(0.7 \mathrm{~mL})$ containing $30 \mathrm{ng}$ of VEGF was injected subcutaneously into wild-type (WT) and K0 mice. Seven days later, the Matrigel plugs were removed and photographed. The histograms represent hemoglobin content determined using the Drabkin method and presented as micrograms of hemoglobin per milligrams of plug. Results here are from one representative experiment of a total of two that were performed. Data are expressed as means \pm SD $(n=12)$. Increased expression of transforming growth factor TGF- $\beta$-related genes and VEGF in injured KO corneas. RNA extracted from control and injured mice at days 2 and 7 after alkali burn underwent real-time quantitative (qPCR) analysis. mRNA levels of TGF- $\beta$, collagen type 1, matrix metalloproteinase MMP-9, and VEGF were analyzed using qPCR. Bars represent specific mRNA levels relative to the level of glyceraldehyde-3-phosphate dehydrogenase (GAPDH) mRNA in the same samples. Data are expressed as means \pm SD. All experiments were performed in triplicate ( $n=6$ for each group). All statistical analyses were computed using Student's $t$-test (two-tailed distribution, equal variance). ${ }^{*} P<0.05$, $* * P<0.005$. 
$0.5 \mathrm{mg} / \mathrm{mL}$, yielding a final cell concentration of $1.5 \times 10^{5} /$ $\mathrm{mL}$ in Dulbecco's modified Eagle's medium, $0.2 \%$ FBS, and antibiotics. TGF- $\beta$ was added to the cells to a concentration of $2.5 \mathrm{ng} / \mathrm{mL}$, and the suspension was seeded in a $24-$ well plate. After 1 hour of incubation at $37^{\circ} \mathrm{C}$ for collagen polymerization, the gelatinous suspension was detached from the well edges by passing a sterile tip along the edge. Results were photo-documented at the indicated time points, and gel contraction was quantified using ImageJ software version $1.47 \mathrm{v}$ (NIH, Bethesda, MD).

\section{PPM1A in Vitro Dephosphorylation Assay}

Human embryonic kidney 293T cells were transfected with a constitutively active TGF- $\beta$ receptor. ${ }^{41}$ Forty-eight hours after transfection, the cells were treated with $0.7 \mathrm{~mol} / \mathrm{L}$ sorbitol for 30 minutes. p38 and Smad3 were immunoprecipitated separately from cell extracts using the appropriate antibodies linked to protein A agarose beads. Immobilized p38 or Smad3 were resuspended in $50 \mu \mathrm{L}$ of phosphatase reaction buffer (50 $\mathrm{mmol} / \mathrm{L}$ Tris, $0.1 \mathrm{mmol} / \mathrm{L}$ EGTA, $\mathrm{pH}$ 7.5) containing the indicated amounts of purified recombinant PPM1A, with or without $30 \mathrm{mmol} / \mathrm{L} \mathrm{MgCl}_{2}$, and incubated for 30 minutes at $30^{\circ} \mathrm{C}$. The reaction was terminated by removal of the reaction mix, addition of $30 \mu \mathrm{L}$ of SDS-PAGE sample buffer, and boiling for 4 minutes. Samples were subjected to Western blot analysis and challenged with anti-phospho-p38 and phosphoSmad3 and total anti-p38 and Smad3 antibodies.

\section{Statistical Analysis and Quantification}

Quantification of positive fluorescence in the paraffin sections was detected using a Meta laser-scanning confocal microscope. The pixel intensity of Mac-3, $\alpha$-SMA, and proliferating cell nuclear antigen was measured with an ImageJ software version 1.47v plugin (cell counter) (NIH, Bethesda, MD) as number of positive cells per square millimeter. VEGF pixel intensity was measured relative to the DAPI staining.

Statistical analysis included Student's $t$-test with a twotailed distribution or as noted in the figure legends. Statistical significance was defined as $P<0.05$. To evaluate whether WT and KO cells differed in their response to TGF$\beta$-mediated p38 and Smad3 phosphorylation, data for the two groups were compared using two-way analysis of variance with time and group as factors. An interaction between these factors with a $P<0.05$ was interpreted as a difference between groups. Analysis of variance was performed using SPSS software version 15 (SPSS Inc, Chicago, IL).

\section{Results}

\section{Generation of PPM1A K0 Mice}

PPM1A is suggested to be engaged in signaling pathways associated with inflammation ${ }^{20}$; to study its possible involvement in vivo, we generated conditional PPMIA KO mice using homologous recombination in mouse ES cells. Mice containing the floxed PPMIA allele were mated with PGK-Cre mice, ${ }^{36}$ which express the Cre recombinase under the PGK promoter normally activated in diploid primordial germ cells. ${ }^{36}$ The PGK-Cre activity led to deletion of exon 2 of PPM1A in the $P P M 1 A^{--;} P G K$-Cre mice, resulting in $\mathrm{KO}$ allele (Figure 1A). WT and PPMIA KO alleles were identified by Southern blot hybridization using $3^{\prime}$ probe (Figure 1B). Immunoblot analysis of protein extracts from WT and KO mice tails, further confirmed the loss of PPM1A protein (Figure 1C). The PPM1A KO mice were viable and fertile, similar to the PPM1A KO mice described recently. ${ }^{29}$ Interestingly, despite the pronounced expression of PPM1A in a variety of ocular tissues, including the retina and corneal epithelium (Figure 1D), the absence of PPM1A did not profoundly affect the histology of the healthy eye (data not shown).

\section{PPM1A Down-Regulates Angiogenesis}

Analysis of the corneal healing process in WT and PPM1Aablated KO mice revealed that although the WT corneas healed, the inflammation in the KO corneas worsened, and 22 days after injury most of the mice developed corneal neovascularization (Figure 2A), with increased neovascularization visible as early as 7 days after wounding (Figure 2A). Histologic and pathologic assessment followed by IHC analysis revealed that impaired wound healing could already be detected at day 2 after injury by the appearance of epithelial defects, stromal thickness, central ulceration with degraded stroma, and increased numbers of inflammatory cells (Figure 2, B and C, and Supplemental Figure S2). The infiltrating inflammatory cells included monocytes and mononuclear phagocytes immunostained by Mac-3 (Figure 3A and Supplemental Figure S2) and dividing stromal cells expressing proliferating cell nuclear antigen (Figure 3B).

$\alpha$-SMA is considered a hallmark of keratocyte transdifferentiation to myofibroblast and scar tissue formation. ${ }^{31,32}$ Indeed, the number of cells expressing high levels of $\alpha$-SMA was also noticeably enhanced in the KO injured corneas (Figure $3 \mathrm{C}$ ). By day 22, when the WT mice properly healed, the KO mice exhibited irregularity of the epithelium, inflammation, and stromal edema (Figure 2, B and D-E, and Supplemental Figure S2). The fibrotic stroma contained dividing inflammatory cells and keratocytes (Figure 3, A-C). The aberrant healing in the KO mice was associated with high expression of VEGF (Figure 3D), a high number of endothelial cells (Figure 3E), and subsequently the appearance of new blood vessels (Figure 2, B and E, Figure 3E, and Supplemental Figure S2). The abnormal healing process and enhanced neovascularization in the absence of PPM1A imply a novel role for PPM1A in restraining the inflammation process and the suppression of new blood vessel formation on injury.

To examine whether PPM1A is a general negative regulator of angiogenesis in vivo, WT and $\mathrm{KO}$ mice were 
injected subcutaneously with Matrigel plugs that contained VEGF. The plugs harvested from the KO mice revealed a $44 \%$ increase in the amount of hemoglobin compared with the WT plugs, thus revealing enhanced angiogenesis in the absence of PPM1A (Figure 3F). Taken together, our findings reveal that PPM1A plays an important role in controlling angiogenesis.

The increased inflammatory response, the high levels of VEGF, and the enhanced angiogenesis may all result from overactivated TGF- $\beta$ signaling in the KO mice. ${ }^{42-47}$ Moreover, earlier studies suggested the role of PPM1A in TGF- $\beta$ signaling. ${ }^{21}$ To examine this hypothesis, we studied the expression of TGF- $\beta$-related genes in the corneas of PPMIA KO mice. Indeed, 2 days after alkali burn, we detected enhanced transcription of TGF- $\beta$ regulated genes, including TGF- $\beta$, Coll, MMP9, and VEGF, in the KO corneas compared with controls (Figure 3G). The levels of TGF- $\beta$ and collagen type 1 remained higher in the KO corneas for as long as 7 days after injury. The levels of these genes were similar in the uninjured WT and PPMIA KO mice.

\section{PPM1A Controls TGF- $\beta$ Signaling in Corneal Keratocytes by Dephosphorylation of $\mathrm{p} 38$}

Stromal keratocytes are central to tissue repair during corneal healing and are known to play a major role in corneal neovascularization and in the angiogenic process. ${ }^{48,49}$ Addition of TGF- $\beta$ mediates the transition of activated fibroblasts to myofibroblasts in vitro. ${ }^{50}$ In view of the enhanced appearance of $\alpha$-SMA-expressing cells in the stroma of the wounded $\mathrm{KO}$ mice and the enhanced expression of TGF- $\beta$ responsive genes in the PPM1A-ablated corneas, we used primary keratocytes cultures to study the mechanism by which PPM1A affects TGF- $\beta$ signaling.

In the canonical TGF- $\beta$ signaling, Smad $2 / 3$ is phosphorylated, whereas in the noncanonical signaling, p38 undergoes phosphorylation. Interestingly, several studies suggest each or both phospho-proteins as PPM1A substrates. ${ }^{21,23,25-28}$ To investigate the way in which these two TGF- $\beta$ targets are affected by PPM1A ablation, we examined their phosphorylation patterns in TGF- $\beta$-treated WT and KO keratocytes. Interestingly, the state of p38 phosphorylation was found to be the most affected by the absence of PPM1A. In the KO cells, phospho-p38 was significantly active even in the untreated state, and its phosphorylation further increased immediately after TGF- $\beta$ treatment (Figure 4, A-C), reaching maximal activation 30 to 60 minutes after TGF- $\beta$ addition. In the treated WT cells, p38 phosphorylation was gradual and relatively moderate, reaching its peak several hours after the treatment. A compiled analysis of 10 independent experiments clearly revealed that in the absence of PPM1A p38 is more activated in the untreated cells and the TGF- $\beta$-treated cells 30 minutes after the treatment (Figure 4C). These findings were further supported on examination of the phosphorylation state of the direct p38 substrate, ATF-2 (Figure 4D). The level of phospho-ATF-2 was higher in both the untreated and TGF- $\beta$-treated PPM1A null cells.

Unexpectedly, the increase in Smad3 phosphorylation and the kinetics of its activation immediately after TGF- $\beta$ treatment were similar in both cell types and were not affected by the absence of PPM1A (Figure 4, A-C). Interestingly, although the level of phospho-Smad in the WT cells declined an hour after the treatment, enhanced phospho-Smad levels were maintained in the KO fibroblasts throughout the experiment, possibly as a result of a secondary response to the overactivated TGF- $\beta$ signaling due to the enhanced phpospho-p38 activation.

Still, acting as an Smad phosphatase, PPM1A could directly affect the rate of phospho-Smad3 dephosphorylation. To examine this issue, we shortly pulsed the cells with TGF- $\beta$ to generate a pool of phospho-Smad3. TGF- $\beta$ was then washed out and TGF- $\beta$ receptor I kinase inhibitor SB431542 was added to the culture medium to prevent Smad3 rephosphorylation. Both the activation and the decay of phospho-Smad3 were similar in the WT and the PPM1Aablated keratocytes and were not affected by the absence of PPM1A (Figure 4, E and F). SB431542 did not affect either p38 activation or its dephosphorylation (Figure 4, E and F), and enhanced p38 phosphorylation was observed in the PPM1A- ablated fibroblasts similarly to that detected on undisrupted TGF- $\beta$ treatment (Figure $4, \mathrm{~A}-\mathrm{C}$ ).

Phospho-p38 is the preferred PPM1A substrate even in vitro. We compared the half maximal inhibitory concentration of both phospho-p38 and phospho-Smad3 using recombinant PPM1A and purified phosphorylated targets. The half maximal inhibitory concentration of phosphoSmad3 was approximately fivefold higher than that of phospho-p38 (360 nmol/L and $70 \mathrm{nmol} / \mathrm{L}$, respectively), pointing at phospho-p38 as the preferred PPM1A substrate (Figure 4, G and $\mathrm{H}$ ).

After TGF- $\beta$ treatment, enhanced PPM1A expression was observed in the WT cells (Figure 4, A and E) similarly to that observed in vivo in the injured cornea (data not shown). Moreover, the pattern of PPM1A induction was similar to that of MAPK p38 phosphorylation, suggesting a link between the phosphatase and the phosphorylated p38.

\section{PPM1A Controls TGF- $\beta$-Mediated Myofibroblast Transdifferentiation through p38 Dephosphorylation}

Corneal fibroblast transdifferentiation is characterized by increased expression of $T G F-\beta$-related genes. We therefore examined the effect of PPM1A ablation on the expression of TGF- $\beta$ and two of its related genes, ie, MMP9 and VEGF. qPCR revealed augmented activation of these genes in the PPM1A-depleted keratocytes (Figure 5A).

The central role of $\mathrm{p} 38$ in the activation of TGF- $\beta$ signaling in PPM1A-ablated cells was illuminated on exposure of the TGF- $\beta$-treated cells to the $\mathrm{p} 38 \alpha$ - and $\mathrm{p} 38 \beta-$ specific inhibitor SB203580 (Figure 5). Blockade of p38 MAPK substantially inhibited the capacity of TGF- $\beta$ to 
A

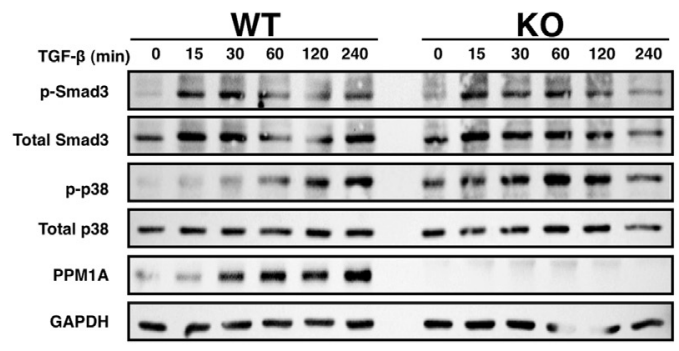

C
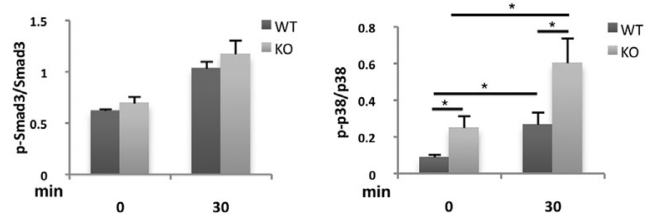

E

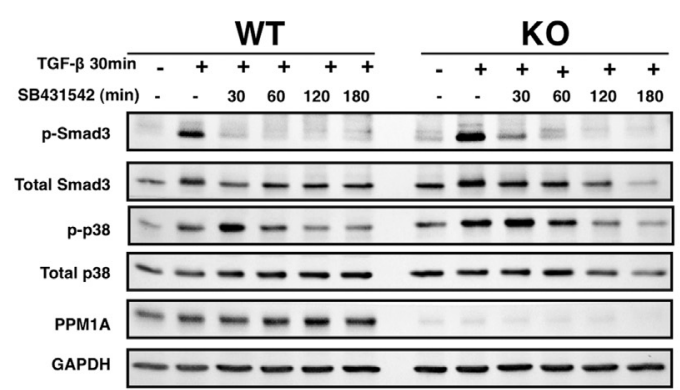

G

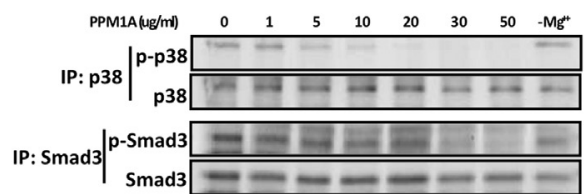

B
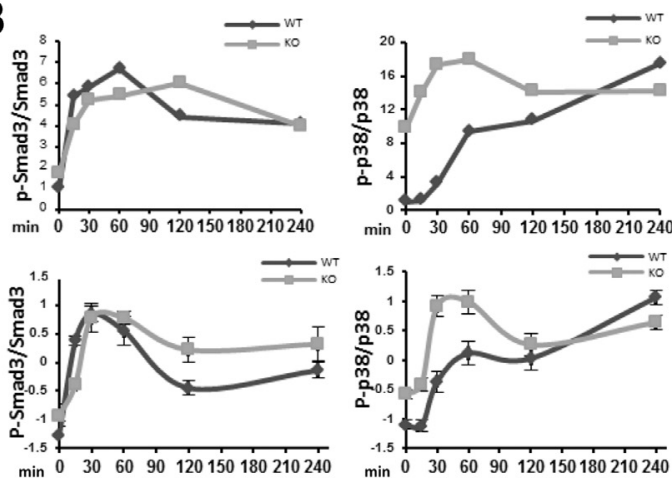

D

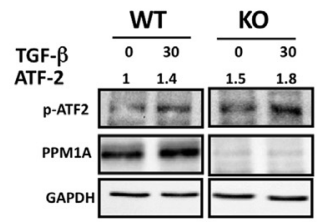

F
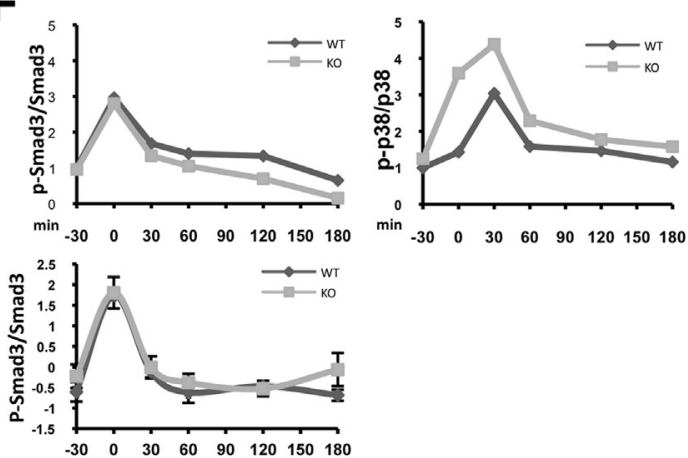

H

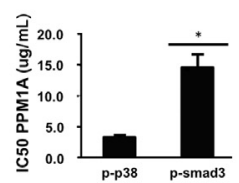

Figure 4 Enhanced p38 activation in PPM1A knockout (K0) corneal fibroblasts treated with transforming growth factor (TGF)- $\beta$. Serum-starved wildtype (WT) and KO corneal fibroblasts were treated with $2.5 \mathrm{ng} / \mathrm{mL}$ of TGF- $\beta$ for the indicated times. Total protein extracts were analyzed by Western blot using the indicated antibodies. A: The blot shows a representative result of seven independent experiments. B: Levels of phospho ( $p$ )-Smad3 and p-p38 in A were quantified and normalized to total Smad3 and p38, respectively (top). C: The curves represent results of seven independent experiments in which the interaction between time and group was analyzed by two-way analysis of variance (bottom). The phosphorylation of p38 in the K0 cells is significantly different from that in the WT cells $(P<0.004)$. However, differences in Smad3 phosphorylation between the WT and K0 were not statistically significant. Data are expressed as means \pm SEM. Serum-starved keratocytes were pulsed with TGF- $\beta$ for 30 minutes or left untreated. Statistical analysis of p-p38 and p-Smad3 activation normalized to p38 and Smad3, respectively, with or without TGF- $\beta$ stimulation. The histograms present results of 10 independent experiments. D: p-ATF-2 activation; serum-starved keratocytes were pulsed with TGF- $\beta$ for 30 minutes or left untreated. The blot shows a representative result of two independent experiments. E: p-ATF-2 levels were quantified and normalized to total glyceraldehyde-3-phosphate dehydrogenase (GAPDH). Serum-starved keratocytes were pulsed with TGF- $\beta$ for 30 minutes. The medium was replaced and $10 \mu \mathrm{mol} / \mathrm{L}$ SB431542, a TGF- $\beta$ receptor inhibitor, was added for the indicated times. Total protein extracts were analyzed by Western blot using the indicated antibodies. F: p-Smad3 protein levels quantified and normalized to total Smad3 (top). G: Representative results of three independent experiments are shown (bottom). No statistical differences were observed between the WT and K0 in Smad3 dephosphorylation pattern (two-way analysis of variance). p-p38 is the favored PPM1A substrate in vitro. H: 293 T cells were transfected with a plasmid expressing a constitutively active TGF- $\beta$ receptor. ${ }^{41}$ Forty-eight hours after transfection the cells were treated with sorbitol, and p38 and Smad3 were immune immobilized. Immobilized p-p38 and p-Smad3 were dephosphorylated with recombinant PPM1A and subjected to Western blot analysis, reacted with anti-p-p38 and anti-p-Smad3 antibodies, and normalized to total p38 and Smad3, respectively. The histogram represents results of three independent experiments. Statistical analyses were performed with Student's $t$-test (one-tailed distribution equal variance). ${ }^{*} P<0.05$. IC50, half maximal inhibitory concentration; IP, immunoprecipitation; $-\mathrm{Mg}^{++}$, without $\mathrm{MgCl}_{2}$. 

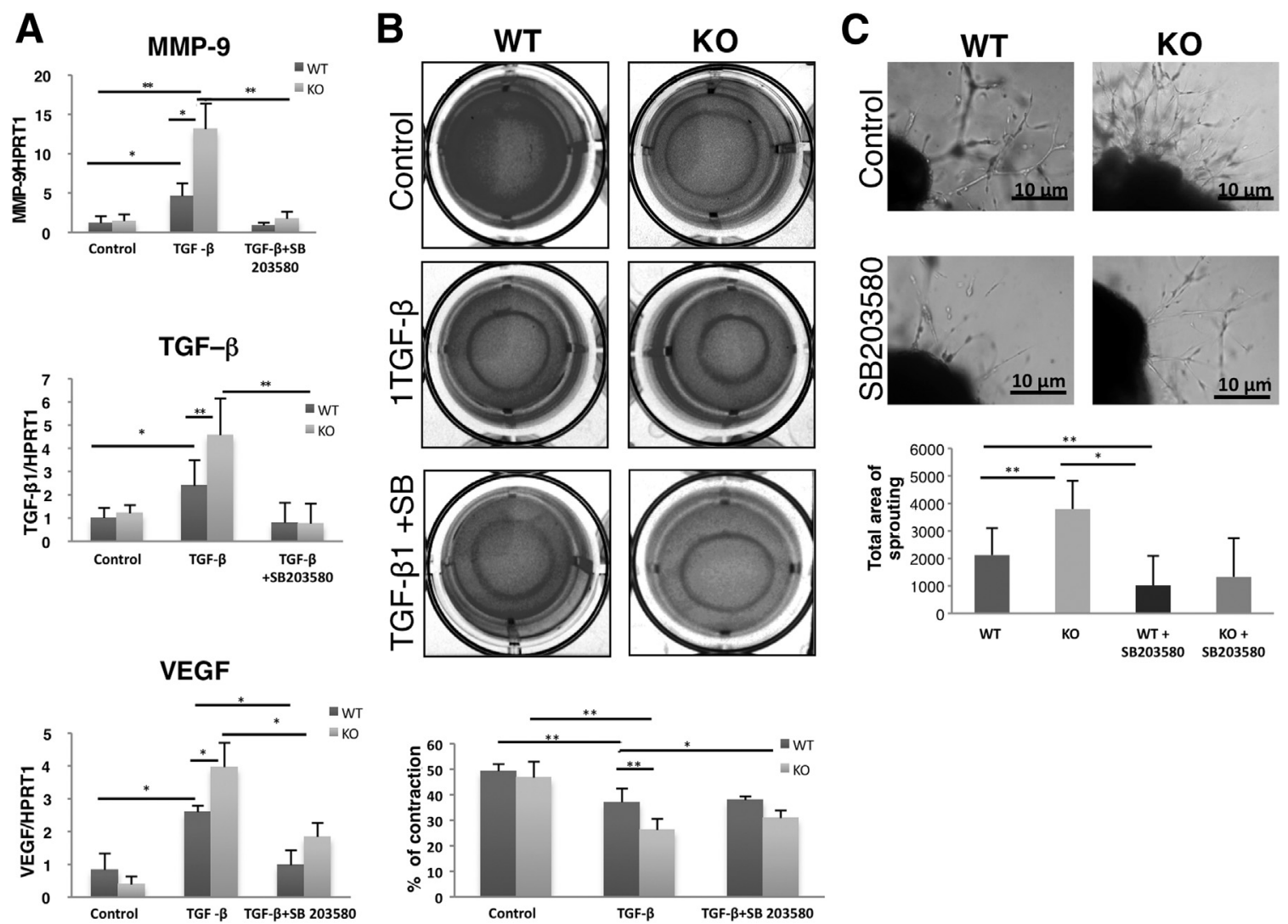

Figure 5 PPM1A regulates transforming growth factor (TGF)- $\beta$ response through $p 38$ dephosphorylation. Serum-starved primary corneal fibroblasts pretreated with $10 \mu \mathrm{mol} / \mathrm{L}$ SB203850 or left untreated for 1 hour were exposed to TGF- $\beta$. Total RNA was extracted at each time point and real-time quantitative PCR was performed. A: Transcription of MMP-9 and TGF- $\beta$ was determined after 24 hours and vascular endothelial growth factor (VEGF) after 8 hours. Bars represent the specific mRNA amount relative to hypoxanthine phosphoribosyltransferase 1 (HPRT1) mRNA in the same samples. All experiments were performed in triplicate. B: Primary ocular fibroblasts were treated as in A and seeded in collagen lattices in serum starvation medium. The experiments were performed in triplicate. Lattices were photo-documented after 24 hours and measured using ImageJ software, and quantification of sprout area was performed with ImageJ software version 1.47v. C: The histogram shows the percentage of matrix area relative to initial gel area, based on three independent experiments. PPM1A regulates angiogenesis through p38 dephosphorylation. Wild-type (WT) and PPM1A knockout (KO) aortic ring explants were seeded in Matrigel with or without $10 \mu \mathrm{mol} / \mathrm{L} \mathrm{SB203580}$ for 8 days and then photo-documented. The photographs shown are representative of one of three independent experiments $(n=9)$. Quantification of sprout area using ImageJ software. The values represent total sprout area in arbitrary units. Statistical analyses were performed with Student's $t$-test (two-tailed distribution equal variance). ${ }^{*} P<0.05,{ }^{* *} P<0.005$.

up-regulate the expression of $M M P 9$ and $T G F-\beta$, significantly reduced the transcription of VEGF mRNA in the WT and the KO keratocytes, and abolished the differences between the two cell types (Figure 5A).

The transition of fibroblasts to myofibroblasts is also characterized by increased contractile activity. ${ }^{51-53} \mathrm{We}$ investigated the contractility in TGF- $\beta$-treated WT and KO corneal fibroblasts using the floating collagen matrix contraction assay (Figure 5B). Although no significant differences were observed in the contraction of undifferentiated WT and KO keratocytes, TGF- $\beta$ treatment caused an increase in the contractility of the $\mathrm{KO}$ myofibroblasts compared with that of the WT cells. On p38 MAPK inhibition, the differences in the contraction of WT and KO cells disappeared (Figure 5B).

Corneal transdifferentiation is also characterized by cell enlargement and elevated expression of $\alpha$-SMA, which is incorporated into actin stress fibers as part of the contractile apparatus to ensure sufficient wound closure. ${ }^{51-53}$ Although
TGF- $\beta$ treatment induced the assembly of $\alpha$-SMA into organized stress fibers in both WT and KO cells, the PPM1Aablated cells were significantly larger (Supplemental Figure S3). On p38 MAPK blockade, the increase in cell size on TGF- $\beta$ treatment in both WT and KO keratocytes disappeared (Supplemental Figure S3).

All in all, the enhanced keratocyte conversion and the overactivated TGF- $\beta$ signaling in PPM1A-ablated cells highlight the key role of PPM1A in the termination of TGF$\beta$ signaling through phospho-p38 dephosphorylation. Our data are consistent with recent findings by Shukla et al, ${ }^{54}$ who found that myofibroblast conversion by TGF- $\beta$ is p38 dependent, and by Meyer-Ter-Vehn, who found that p38 inhibitors prevented myofibroblast conversion of human tendon fibroblasts. ${ }^{55}$

To examine whether the enhanced angiogenesis in the absence of PPM1A is also controlled by the activated p38, we used the ex vivo aortic ring assay to analyze sprout formation in cultured WT and KO aortas. PPM1A KO 
aortas displayed an increased number of sprouts with longer and more branched extensions, demonstrating accelerated angiogenesis ex vivo (Figure 5C). The augmented sprout formation was also dependent on enhanced p38 activation because MAPK blockade almost completely abolished sprouting in both WT and $\mathrm{KO}$ aortic rings.

\section{Discussion}

Despite the participation of PPM1A in key cellular processes and the multiple proteins suggested as its substrates, the physiologic role of this phosphatase has been a riddle because of the lack of specific inhibitor(s). ${ }^{17}$ To unravel this mystery, PPM1A KO mice were generated in our laboratory. To circumvent the possibility of embryonic lethality, we used the conditional KO approach. Fully ablated PPM1A KO mice were born alive, exhibited normal development, and were fertile, revealing that PPM1A is not essential for the development and the maturation of apparently healthy mice.

In the current study, using in vivo, ex vivo, and in vitro experimental models, we have identified PPM1A as a novel regulator of the inflammation-angiogenesis cross talk on injury. The lack of PPM1A in the KO mice led to a continuous inflammatory response, augmented p38 MAPK activation, elevated expression of TGF- $\beta$-related genes, and subsequently led to the formation of new blood vessels. Using corneal keratocytes, we have found that in the absence of PPM1A the keratocytes underwent enhanced activation and maturation, resulting from overactivated TGF- $\beta$ signaling cascade due to augmented p38 MAPK signaling.

\section{PPM1A Plays a Crucial Role in Homeostasis on Injury}

Inflammation is a complex cascade that involves the elevated expression of transcription factors, release of chemokines and cytokines, and the recruitment of inflammatory cells that further induce transcription factors, causing enhanced tissue modulation. ${ }^{56}$ One outcome of enhanced inflammation is angiogenesis, the formation of new blood vessels, which is regulated by the very sensitive interplay between antiangiogenic and proangiogenic factors, of which VEGF is a key regulator. ${ }^{3}$

The highly specialized structure of the cornea is transparent and avascular and is therefore an excellent model for the study of inflammation and angiogenesis. ${ }^{14} \mathrm{We}$ have used the corneal alkaline burn experimental model to study the role of PPM1A in inflammation. The lack of PPM1A led to uncontrolled inflammatory response that could be detected as early as 2 days after injury. The burnt KO corneas displayed high stromal activation, including enhanced macrophage and monocyte infiltration, high levels of proliferating cells, and increased keratocyte differentiation, processes that are known to be regulated in the wounded tissues by cytokine release. ${ }^{57}$
The injured PPM1A-ablated corneas revealed delayed epithelial closure consistent with the recently reported effect of PPM1A deficiency on cutaneous wound healing. ${ }^{29}$ Defective wound closure affects the stroma and contributes to keratocyte activation through cytokine release. ${ }^{31}$ Indeed, we have found that TGF- $\beta$ and its downstream targets were up-regulated in the absence of PPM1A, allowing a burst of inflammatory response in the $\mathrm{KO}$ mice. The enhanced transcription of the proinflammatory and proangiogenic genes TGF- $\beta$, CollA, MMP9, and VEGF led to uncontrolled inflammation, stromal tissue disorganization, and fibrosis. Subsequently, high expression of VEGF, the main angiogenesis effector, led to unrestrained neovascularization characterized by the appearance of new blood vessels. The increased PPM1A expression in the wounded corneal tissues during the healing process further emphasizes its key role in maintaining homeostasis after injury and in restraining the uncontrolled activation of proinflammatory factors, such as TGF- $\beta$ and $\mathrm{p} 38 .{ }^{42,46,58} \mathrm{We}$ propose that by this mode of operation PPM1A prevents the escalation of the inflammatory response to angiogenesis on injury. Our findings indicate that augmented angiogenesis in the absence of PPM1A is a general phenomenon that occurs in vivo in the $\mathrm{KO}$ mice on subcutaneous injection of Matrigel and ex vivo in the aortic ring assay.

\section{PPM1A Regulates TGF- $\beta$ Signaling in Stromal Keratocytes via p38 Dephosphorylation}

Stromal keratocytes are known to play a key role in angiogenesis. ${ }^{48,49}$ In view of our in vivo findings revealing their pronounced transactivation and the enhanced TGF- $\beta$ signaling in the PPM1A-ablated corneas, we aimed to identify the direct PPM1A substrate(s) using primary corneal keratocyte cultures. Two major signaling cascades are stimulated on the activation of TGF- $\beta$ receptor, the canonical Smad2/3 and the noncanonical TAK1/p38 ${ }^{59}$; both were found in multiple reports to be PPM1A substrates. ${ }^{21,23,27}$ Using numerous experimental approaches, we have found that PPM1A mainly affects p38 and that its impact on the TGF- $\beta$ response is through the dephosphorylation of phospho-p38. Our conclusion is based on the following findings. First, p38 was already activated in the untreated primary KO keratocytes and was further activated on TGF- $\beta$ treatment, reaching a peak 30 minutes after its addition. In the untreated WT cells, phospo-p38 levels were marginal and after TGF- $\beta$ addition increased gradually for at least 4 hours (Figure 4, A-C, E, and F). Second, the levels of phospho-ATF-2, the direct p38 substrate, were higher in the untreated and TGF- $\beta$-treated PPM1A-ablated cells (Figure 4D). Third, the $\mathrm{p} 38 \alpha / \beta$ inhibitor SB203580 abolished the augmented TGF- $\beta$ response in the KO cultures and the enhanced activation of the TGF- $\beta$-activated genes $M M P 9, T G F-\beta$, and VEGF (Figure 5A), enhanced keratocyte contraction (Figure 5B), and increased cell size (Supplemental Figure S3). Similarly, SB202190, the 38a 
and $\beta$ inhibitor, abolished $\mathrm{p} 38$ activation in the TGF$\beta$-treated cells, suggesting that PPM1A affects p38 $\alpha$ and $\beta$ isoforms (data not shown). In addition, we found that PPM1A expression increased concomitantly with p38 activation, revealing the interplay between PPM1A elevation and p38 MAPK dephosphorylation.

Unexpectedly, we found that the kinetics of phosphoSmad3 activation and decay were similar in untreated and TGF- $\beta$-treated WT and KO keratocytes. Even in the in vitro dephosphorylation assay, where recombinant PPM1A was used to dephosphorylate both substrates, phospho-p38 was found to be a better PPM1A substrate (Figure 4, G and H).

All in all, our data indicate that in the TGF- $\beta$-treated keratocyte phospho-p38 served as the preferred PPM1A substrate. Recent studies by Shukla et $\mathrm{al}^{54}$ on the role of CLIC4 in TGF- $\beta$ signaling have found that in murine primary dermal fibroblasts TGF- $\beta$-dependent induction of $\alpha$-SMA and fibroblasts maturation occurs via p38 MAPK activation. Moreover, the authors attributed the effect of CLIC4 on p38 MAPK activation to the reduced interaction of phospho-p38 with PPM1A in the presence of CLIC4. Future studies using

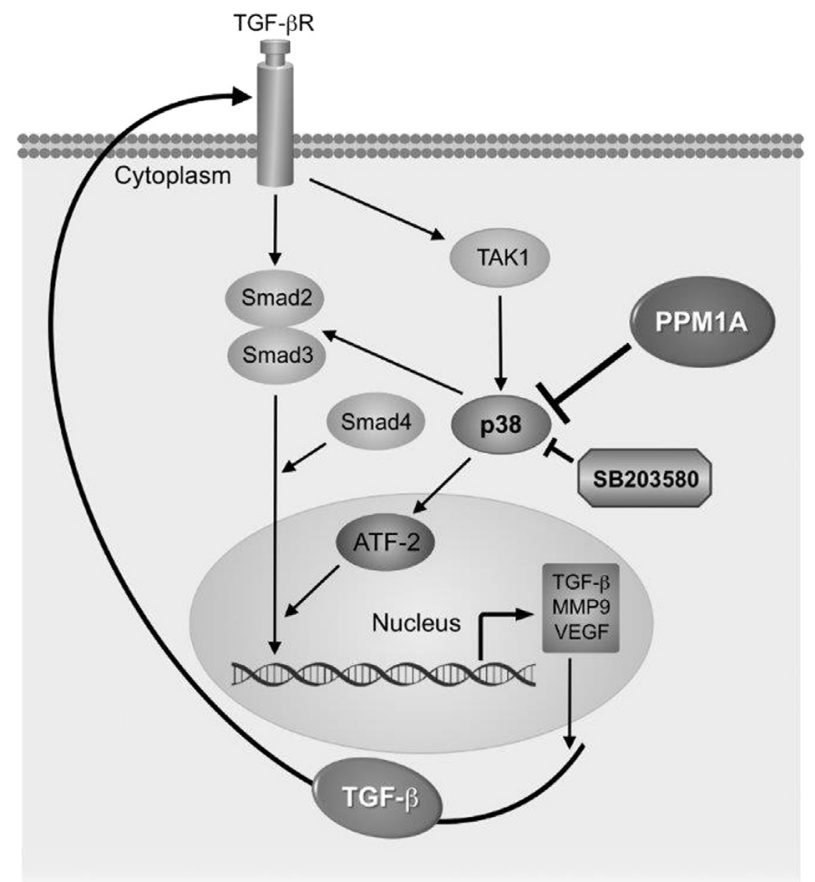

Figure 6 Model representing the role of PPM1A in the termination of the transforming growth factor (TGF)- $\beta$ signaling. On the activation of the TGF- $\beta$ receptor, two signaling pathways are activated (ie, the canonical Smad2/3 and the noncanonical TAK1/p38). We propose that PPM1A specifically dephosphorylates the activated $\mathrm{p} 38$, rendering it amenable to further phosphorylation in the presence of activating signal. This interplay continues as long as the activating signal persists. However, in the absence of PPM1A, p38 is overactivated, leading to enhanced transcription of TGF- $\beta$-related genes, including TGF- $\beta 1$, MMP9, VEGFTGF- $\beta 1$, MMP9, and VEGF. The increased level of TGF- $\beta$ reactivates the TGF- $\beta$ receptor, which in turn refuels both arms of the TGF- $\beta$ signaling, leading to the augmented TGF- $\beta$ response. SB203580, a specific p38 inhibitor, abolishes the differences between the wild-type and knockout mice and turns off the TGF- $\beta$ signaling cascade.
PPM1A KO dermal fibroblasts will illuminate the effect of these interactions. The role of p38 in fibroblast maturation was further reported by Meyer-ter-Vehn et al, ${ }^{55}$ who found that p38 inhibitors prevented myofibroblast conversion of human tendon fibroblasts.

PPM1A might regulate Smad3 in a dephosphorylationindependent manner through protein-protein interaction as previously reported for Smad1 and p53. ${ }^{60}$ However, it was recently reported that protein phosphatase 5 , and not PPM1A, interacts with $\operatorname{Smad} 2 / 3$ and thus regulates their expression. ${ }^{61}$ In addition, PPM1A may act on additional substrates. Our findings that p38 inhibition did not completely abolish VEGF transcription (Figure 5A) and enhanced collagen contraction (Figure 5B) support this notion. Indeed, JNK, phosphatidylinositol 3-kinase, and NF- $\mathrm{B}$, signaling pathways that regulate VEGF transcription, were all suggested as PPM1A substrates. ${ }^{17,62}$ Note that PPM1A can control phospho-p38 through its direct dephosphorylation and/or through the dephosphorylation of its upstream kinases TAK1 and MPKKs that control its phosphorylation. ${ }^{25,27,28,63}$ Further studies, which are beyond the scope of the current report, are required to solve this issue.

\section{PPM1A Acts as p38 Inhibitor on Injury}

The $\mathrm{p} 38$ family of MAPKs mediates signaling in response to environmental stresses and inflammatory cytokines. Downregulation of p38 MAPKs is critical for the achievement of short-term activation and regulation of signal strength, which in turn results in specific outcomes and eventually leads to homeostasis. ${ }^{64}$ Several phosphatases were suggested to terminate p38 catalytic activity through the dephosphorylation of the activation loop threonine and tyrosine residues. These phosphatases include PP2A and members of the PPM1 family, such as PPM1A, PPM1B, and WIP1, that dephosphorylate the threonine residues. The activity of MAPKs was found to be regulated by a family of dual-specificity phosphatases that dephosphorylate threonine and tyrosine residues. ${ }^{65,66}$ Interestingly, in all our experiments, in vivo and in vitro, the overactivated p38 was controlled only by PPM1A, with no apparent complementation by its paralogs PPM1B and PPM1D or by other phosphatases found earlier to dephosphorylate p38. ${ }^{17}$

On the basis of our findings, we propose that on injury PPM1A serves as phospho-p38 phosphatase, thus restraining its activity as the transcriptional regulator of proinflammatory and proangiogenic genes (Figure 6). Furthermore, we have found that the enhanced ex vivo angiogenesis occurring in the $\mathrm{KO}$ aortic rings is controlled by augmented p38 activation and that treatment with a p38-specific inhibitor completely abolished the enhanced angiogenesis and canceled the differences between the WT and the KO aortas. In view of the role of p38 in healing, inflammation, and angiogenesis, its elevated level in the injured WT corneas is expected because its function is essential for proper healing. ${ }^{58,67}$ However, the unrestrained p38 phosphorylation and activation (data not 
shown), as well as the elevated expression of the p38regulated genes, including MMP9, VEGF, Coll, and $T G F-\beta^{68-70}$ accompanied by the very severe pathology in the KO corneas all attest to the physiologic role of PPM1A as major $\mathrm{p} 38$ phosphatase on wound healing.

We suggest that, after TGF- $\beta$ activation in injured cornea or on keratinocyte treatment with TGF- $\beta$, PPM1A dephosphorylates the activated p38 MAPK and thus renders it amenable for rephosphorylation by its activating kinase; PPM1A expression is essential to down-regulate the activated p38 MAPK. This interplay between PPM1A and its substrate continues as long as the cues activating p38 MAPK are present. On healing, the inducing signals subside, PPM1A completes its task, its level is reduced, and tissue homeostasis is restored. In the absence of PPM1A, p38 signaling that could not be properly terminated remains activated, thus producing excessive levels of TGF- $\beta$ that continuously activate the TGF- $\beta$ receptor and leads to constant phospho-Smad and phospho-p38 activation (Figure 4, A-F). Such aberrant stimulation of TGF- $\beta$ leads to continuous induction of TGF- $\beta$ signaling (and possibly other yet unknown signaling pathways); imbalanced production of TGF- $\beta$, VEGF, and other proangiogenic factors; and finally to deregulated angiogenesis (Figure 6).

The role of PPM1A in sustaining homeostasis on injury, its role as a regulator of angiogenesis, and the mechanism of its action could not have been discovered but for the use of the PPM1A-ablated mice in which p38 MAPK signaling cascade is constitutively activated after injury.

\section{PPM1A Regulation}

In view of its importance in maintaining cellular homeostasis on healing and the uncontrolled inflammation and angiogenesis that ensue in its absence, PPM1A expression and activity should be regulated and tightly controlled. In the experiments reported here, as well as in earlier studies, enhanced PPM1A expression in response to external cues was detected. ${ }^{22,71,72}$ Numerous modes of regulation were suggested to control PPM1A expression at both mRNA and protein levels. Several reports found elevated PPM1A transcription on cell differentiation, ${ }^{22,73}$ and we have also recently found enhanced mRNA levels during oocyte maturation. ${ }^{73}$ Alternatively, PPM1A could be regulated through its subcellular localization.

We have recently reported that in undifferentiated PC12 cells PPM1A is expressed exclusively in the cytoplasm, whereas on differentiation it is present in both the cytoplasm and nucleus. ${ }^{72}$ Moreover, during hepatocarcinoma progression, PPM1A expression was shifted from the nucleus to the cytoplasm. ${ }^{74}$ The stability of the PPM1A protein was found to be regulated through its association with PTEN in TGF$\beta$-treated cells. ${ }^{75}$ PPM1A was also found to be phosphorylated, although this phosphorylation was not found to affect its activity. ${ }^{71}$ PPM1A expression can be artificially activated; agents such as D-chiro-inositol-galactosamine, a putative mimetic of insulin action, and NPLC0393, a small molecular agent, were found to activate PPM1A in mice and thus might be therapeutically beneficial. ${ }^{27,76}$ Differences in the PPM1A response of individuals to cellular cues might affect their predisposition to inflammation and angiogenesis, as well as other yet unknown diseases. Indeed, converging evidence from mice and humans suggests a role for PPM1A in the response to the noradrenergic antidepressant drug nortriptyline, and patients with specific polymorphisms in PPM1A were significantly associated with positive response to the drug. ${ }^{77}$

In this study, we introduced PPM1A as a major regulator in the interplay between inflammation and angiogenesis and found that via p38 dephosphorylation PPM1A restrains this delicate cross talk and terminates the TGF- $\beta$ response. These findings reveal that the fine-tuning of PPM1A is critical to maintain homeostasis. The new knowledge regarding PPM1A may contribute to the understanding of angiogenesis in specific cases, such as age-related macular degeneration, but also can have implications for more general fields, such as cancer research and treatment. Artificial intervention in PPM1A expression using agents capable of activating its expression may control inflammation, reduce angiogenesis, and contribute to the treatment of multiple diseases associated with these processes.

\section{Acknowledgments}

We thank Dr. Alexandra Joyner for the plasmid that was used in the construction of the targeting vector, Prof. Mia Horowitz and Dr. Debora Rapaport for their help and advice in the construction of the targeting vector, Dr. Rebecca Hafner for help in the generation of the KO mice, Drs. Dan Frenkel and Ariel Munitz for support and advice, and Dr. Anat Nitzan and Chana Ziv for technical assistance. We also thank Dr. Doron Calo for critically reading of the manuscript.

\section{Supplemental Data}

Supplemental material for this article can be found at http://dx.doi.org/10.1016/j.ajpath.2014.07.022.

\section{References}

1. Carmeliet P: Angiogenesis in life, disease and medicine. Nature 2005 , 438:932-936

2. Alvarado-Kristensson M, Andersson T: Protein phosphatase 2A regulates apoptosis in neutrophils by dephosphorylating both p38 MAPK and its substrate caspase 3. J Biol Chem 2005, 280: 6238-6244

3. Hoeben A, Landuyt B, Highley MS, Wildiers H, Van Oosterom AT, De Bruijn EA: Vascular endothelial growth factor and angiogenesis. Pharmacol Rev 2004, 56:549-580

4. Mousa SA, Mousa SS: Current status of vascular endothelial growth factor inhibition in age-related macular degeneration. BioDrugs 2010 , 24:183-194 
5. Carmeliet P, Jain RK: Angiogenesis in cancer and other diseases Nature 2000, 407:249-257

6. Iruela-Arispe ML, Dvorak HF: Angiogenesis: a dynamic balance of stimulators and inhibitors. Thromb Haemost 1997, 78:672-677

7. Avraamides CJ, Garmy-Susini B, Varner JA: Integrins in angiogenesis and lymphangiogenesis. Nat Rev Cancer 2008, 8:604-617

8. Folkman J: Angiogenesis in cancer, vascular, rheumatoid and other disease. Nat Med 1995, 1:27-31

9. Angelo LS, Kurzrock R: Vascular endothelial growth factor and its relationship to inflammatory mediators. Clin Cancer Res 2007, 13: $2825-2830$

10. Rosen LS: VEGF-targeted therapy: therapeutic potential and recent advances. Oncologist 2005, 10:382-391

11. Esposito I, Menicagli M, Funel N, Bergmann F, Boggi U, Mosca F, Bevilacqua G, Campani D: Inflammatory cells contribute to the generation of an angiogenic phenotype in pancreatic ductal adenocarcinoma. J Clin Pathol 2004, 57:630-636

12. Arnold F, West DC: Angiogenesis in wound healing. Pharmacol Ther 1991, 52:407-422

13. Bao P, Kodra A, Tomic-Canic M, Golinko MS, Ehrlich HP, Brem H: The role of vascular endothelial growth factor in wound healing. J Surg Res 2009, 153:347-358

14. Paranthan RR, Bargagna-Mohan P, Lau DL, Mohan R: A robust model for simultaneously inducing corneal neovascularization and retinal gliosis in the mouse eye. Mol Vis 2011, 17:1901-1908

15. Fujita S, Saika S, Kao WW, Fujita K, Miyamoto T, Ikeda K, Nakajima Y, Ohnishi Y: Endogenous TNFalpha suppression of neovascularization in corneal stroma in mice. Invest Ophthalmol Vis Sci 2007, 48:3051-3055

16. Philipp W, Speicher L, Humpel C: Expression of vascular endothelial growth factor and its receptors in inflamed and vascularized human corneas. Invest Ophthalmol Vis Sci 2000, 41:2514-2522

17. Lammers $\mathrm{T}$, Lavi $\mathrm{S}$ : Role of type $2 \mathrm{C}$ protein phosphatases in growth regulation and in cellular stress signaling. Crit Rev Biochem Mol Biol 2007, 42:437-461

18. Cohen P: The structure and regulation of protein phosphatases. Adv Second Messenger Phosphoprotein Res 1990, 24:230-235

19. Stern A, Privman E, Rasis M, Lavi S, Pupko T: Evolution of the metazoan protein phosphatase 2C superfamily. J Mol Evol 2007, 64: $61-70$

20. Sun W, Yu Y, Dotti G, Shen T, Tan X, Savoldo B, Pass AK, Chu M, Zhang D, Lu X, Fu S, Lin X, Yang J: PPM1A and PPM1B act as IKKbeta phosphatases to terminate TNFalpha-induced IKKbeta-NFkappaB activation. Cell Signal 2009, 21:95-102

21. Lin X, Duan X, Liang YY, Su Y, Wrighton KH, Long J, Hu M, Davis CM, Wang J, Brunicardi FC, Shi Y, Chen YG, Meng A, Feng XH: PPM1A functions as a Smad phosphatase to terminate TGFbeta signaling. Cell 2006, 125:915-928

22. Yoshizaki T, Maegawa H, Egawa K, Ugi S, Nishio Y, Imamura T, Kobayashi T, Tamura S, Olefsky JM, Kashiwagi A: Protein phosphatase-2C alpha as a positive regulator of insulin sensitivity through direct activation of phosphatidylinositol 3-kinase in 3T3-L1 adipocytes. J Biol Chem 2004, 279:22715-22726

23. Takekawa M, Maeda T, Saito H: Protein phosphatase 2Calpha inhibits the human stress-responsive p38 and JNK MAPK pathways. EMBO J 1998, 17:4744-4752

24. Strovel ET, Wu D, Sussman DJ: Protein phosphatase 2Calpha dephosphorylates axin and activates LEF-1-dependent transcription. J Biol Chem 2000, 275:2399-2403

25. Hanada M, Kobayashi T, Ohnishi M, Ikeda S, Wang H, Katsura K, Yanagawa Y, Hiraga A, Kanamaru R, Tamura S: Selective suppression of stress-f protein kinase pathway by protein phosphatase $2 \mathrm{C}$ in mammalian cells. FEBS Lett 1998, 437:172-176

26. Aburai N, Yoshida M, Ohnishi M, Kimura K: Sanguinarine as a potent and specific inhibitor of protein phosphatase $2 \mathrm{C}$ in vitro and induces apoptosis via phosphorylation of p38 in HL60 cells. Biosci Biotechnol Biochem 2010, 74:548-552
27. Wang L, Wang X, Chen J, Yang Z, Yu L, Hu L, Shen X: Activation of protein serine/threonine phosphatase PP2Calpha efficiently prevents liver fibrosis. PLoS One 2010, 5:e14230

28. Yu Y, Li J, Wan Y, Lu J, Gao J, Huang C: GADD45alpha induction by nickel negatively regulates JNKs/p38 activation via promoting PP2Calpha expression. PLoS One 2013, 8:e57185

29. Yang X, Teng Y, Hou N, Fan X, Cheng X, Li J, Wang L, Wang Y, Wu X: Delayed re-epithelialization in Ppmla gene-deficient mice is mediated by enhanced activation of Smad2. J Biol Chem 2011, 286: 42267-42273

30. Okada Y, Reinach PS, Shirai K, Kitano A, Kao WW, Flanders KC, Miyajima M, Liu H, Zhang J, Saika S: TRPV1 involvement in inflammatory tissue fibrosis in mice. Am J Pathol 2011, 178: 2654-2664

31. Wilson SE, Mohan RR, Ambrosio R Jr, Hong J, Lee J: The corneal wound healing response: cytokine-mediated interaction of the epithelium, stroma, and inflammatory cells. Prog Retin Eye Res 2001, 20:625-637

32. Myrna KE, Pot SA, Murphy CJ: Meet the corneal myofibroblast: the role of myofibroblast transformation in corneal wound healing and pathology. Vet Ophthalmol 2009, 12(Suppl 1):25-27

33. Bazan HE: Cellular and molecular events in corneal wound healing: significance of lipid signalling. Exp Eye Res 2005, 80:453-463

34. Shakiba Y, Mansouri K, Arshadi D, Rezaei N: Corneal neovascularization: molecular events and therapeutic options. Recent Pat Inflamm Allergy Drug Discov 2009, 3:221-231

35. Sgaier SK, Lao Z, Villanueva MP, Berenshteyn F, Stephen D, Turnbull RK, Joyner AL: Genetic subdivision of the tectum and cerebellum into functionally related regions based on differential sensitivity to engrailed proteins. Development 2007, 134: $2325-2335$

36. Lallemand Y, Luria V, Haffner-Krausz R, Lonai P: Maternally expressed PGK-Cre transgene as a tool for early and uniform activation of the Cre site-specific recombinase. Transgenic Res 1998, 7: 105-112

37. Shaham O, Menuchin Y, Farhy C, Ashery-Padan R: Pax6: a multilevel regulator of ocular development. Prog Retin Eye Res 2012, 31:351-376

38. Ofek P, Ben-Meir D, Kariv-Inbal Z, Oren M, Lavi S: Cell cycle regulation and $\mathrm{p} 53$ activation by protein phosphatase $2 \mathrm{C}$ alpha. J Biol Chem 2003, 278:14299-14305

39. Baker M, Robinson SD, Lechertier T, Barber PR, Tavora B, D’Amico G, Jones DT, Vojnovic B, Hodivala-Dilke K: Use of the mouse aortic ring assay to study angiogenesis. Nat Protoc 2011, 7: 89-104

40. Su Y, Cui Z, Li Z, Block ER: Calpain-2 regulation of VEGFmediated angiogenesis. FASEB J 2006, 20:1443-1451

41. Shapira KE, Gross A, Ehrlich M, Henis YI: Coated Pit-mediated endocytosis of the type $\mathrm{i}$ transforming growth factor-beta (TGFbeta) receptor depends on a di-leucine family signal and is not required for signaling. J Biol Chem 2012, 287:26876-26889

42. Han G, Li F, Singh TP, Wolf P, Wang XJ: The pro-inflammatory role of TGFbeta1: a paradox? Int J Biol Sci 2012, 8:228-235

43. Wang XJ, Han G, Owens P, Siddiqui Y, Li AG: Role of TGF betamediated inflammation in cutaneous wound healing. J Investig Dermatol Symp Proc 2006, 11:112-117

44. Bottoms SE, Howell JE, Reinhardt AK, Evans IC, McAnulty RJ: TgfBeta isoform specific regulation of airway inflammation and remodelling in a murine model of asthma. PLoS One 2010, 5:e9674

45. Funaba M, Ikeda T, Murakami M, Ogawa K, Nishino Y, Tsuchida K, Sugino H, Abe M: Involvement of p38 MAP kinase and Smad3 in TGF-beta-mediated mast cell functions. Cell Signal 2006, 18: 2154-2161

46. Yamamoto $\mathrm{T}$, Kozawa $\mathrm{O}$, Tanabe $\mathrm{K}$, Akamatsu S, Matsuno $\mathrm{H}$, Dohi S, Uematsu T: Involvement of p38 MAP kinase in TGF-betastimulated VEGF synthesis in aortic smooth muscle cells. J Cell Biochem 2001, 82:591-598 
47. Ferrari G, Cook BD, Terushkin V, Pintucci G, Mignatti P: Transforming growth factor-beta 1 (TGF-beta1) induces angiogenesis through vascular endothelial growth factor (VEGF)-mediated apoptosis. J Cell Physiol 2009, 219:449-458

48. Hanahan D, Weinberg RA: Hallmarks of cancer: the next generation. Cell 2011, 144:646-674

49. Azar DT: Corneal angiogenic privilege: angiogenic and antiangiogenic factors in corneal avascularity, vasculogenesis, and wound healing (an American Ophthalmological Society thesis). Trans Am Ophthalmol Soc 2006, 104:264-302

50. Fini ME, Stramer BM: How the cornea heals: cornea-specific repair mechanisms affecting surgical outcomes. Cornea 2005, 24:S2-S11

51. Hinz B: Formation and function of the myofibroblast during tissue repair. J Invest Dermatol 2007, 127:526-537

52. Li B, Wang JH: Fibroblasts and myofibroblasts in wound healing: force generation and measurement. J Tissue Viability 2009

53. West-Mays JA, Dwivedi DJ: The keratocyte: corneal stromal cell with variable repair phenotypes. Int J Biochem Cell Biol 2006, 38:1625-1631

54. Shukla A, Edwards R, Yang Y, Hahn A, Folkers K, Ding J, Padmakumar VC, Cataisson C, Suh KS, Yuspa SH: CLIC4 regulates TGF-beta-dependent myofibroblast differentiation to produce a cancer stroma. Oncogene 2013, 33:842-850

55. Meyer-Ter-Vehn T, Gebhardt S, Sebald W, Buttmann M, Grehn F, Schlunck G, Knaus P: p38 inhibitors prevent TGF-beta-induced myofibroblast transdifferentiation in human tenon fibroblasts. Invest Ophthalmol Vis Sci 2006, 47:1500-1509

56. Coussens LM, Werb Z: Inflammation and cancer. Nature 2002, 420 : 860-867

57. Saika S: TGF-beta signal transduction in corneal wound healing as a therapeutic target. Cornea 2004, 23:S25-S30

58. Rajashekhar G, Kamocka M, Marin A, Suckow MA, Wolter WR, Badve S, Sanjeevaiah AR, Pumiglia K, Rosen E, Clauss M: Proinflammatory angiogenesis is mediated by p38 MAP kinase. J Cell Physiol 2011, 226:800-808

59. Zhang YE: Non-Smad pathways in TGF-beta signaling. Cell Res 2009, 19:128-139

60. Chau JF, Jia D, Wang Z, Liu Z, Hu Y, Zhang X, Jia H, Lai KP, Leong WF, Au BJ, Mishina Y, Chen YG, Biondi C, Robertson E, Xie D, Liu H, He L, Wang X, Yu Q, Li B: A crucial role for bone morphogenetic protein-Smad1 signalling in the DNA damage response. Nat Commun 2012, 3:836

61. Bruce DL, Macartney T, Yong W, Shou W, Sapkota GP: Protein phosphatase 5 modulates SMAD3 function in the transforming growth factor-beta pathway. Cell Signal 2012, 24:1999-2006

62. Pages G, Pouyssegur J: Transcriptional regulation of the vascular endothelial growth factor gene-a concert of activating factors. Cardiovasc Res 2005, 65:564-573

63. Hanada M, Ninomiya-Tsuji J, Komaki K, Ohnishi M, Katsura K, Kanamaru R, Matsumoto K, Tamura S: Regulation of the TAK1 signaling pathway by protein phosphatase 2C. J Biol Chem 2001, 276:5753-5759

64. Cuenda A, Rousseau S: p38 MAP-kinases pathway regulation, function and role in human diseases. Biochim Biophys Acta 2007, 1773:1358-1375
65. Dickinson RJ, Keyse SM: Diverse physiological functions for dualspecificity MAP kinase phosphatases. J Cell Sci 2006, 119: 4607-4615

66. Wang Z, Reinach PS, Zhang F, Vellonen KS, Urtti A, Turner H, Wolosin JM: DUSP5 and DUSP6 modulate corneal epithelial cell proliferation. Mol Vis 2010, 16:1696-1704

67. Saika S, Okada Y, Miyamoto T, Yamanaka O, Ohnishi Y, Ooshima A, Liu CY, Weng D, Kao WW: Role of p38 MAP kinase in regulation of cell migration and proliferation in healing corneal epithelium. Invest Ophthalmol Vis Sci 2004, 45:100-109

68. Tsukada S, Westwick JK, Ikejima K, Sato N, Rippe RA: SMAD and p38 MAPK signaling pathways independently regulate alpha1(I) collagen gene expression in unstimulated and transforming growth factor-beta-stimulated hepatic stellate cells. J Biol Chem 2005, 280: $10055-10064$

69. Berra E, Pages G, Pouyssegur J: MAP kinases and hypoxia in the control of VEGF expression. Cancer Metastasis Rev 2000, 19: 139-145

70. Simon C, Simon M, Vucelic G, Hicks MJ, Plinkert PK, Koitschev A, Zenner HP: The p38 SAPK pathway regulates the expression of the MMP-9 collagenase via AP-1-dependent promoter activation. Exp Cell Res 2001, 271:344-355

71. Kobayashi T, Kanno S, Terasawa T, Murakami T, Ohnishi M, Ohtsuki K, Hiraga A, Tamura S: Phosphorylation of $\mathrm{Mg}(2+)$ dependent protein phosphatase alpha (type $2 \mathrm{C}$ alpha) by casein kinase II. Biochem Biophys Res Commun 1993, 195:484-489

72. Shohat M, Ben-Meir D, Lavi S: Protein phosphatase magnesium dependent 1A (PPM1A) plays a role in the differentiation and survival processes of nerve cells. PLoS One 2012, 7:e32438

73. Chuderland D, Dvashi Z, Kaplan-Kraicer R, Ben-Meir D, Shalgi R, Lavi S: De novo synthesis of protein phosphatase 1A, magnesium dependent, alpha isoform (PPM1A) during oocyte maturation. Cell Mol Biol Lett 2012, 17:433-445

74. Wu SK, Wang BJ, Yang Y, Feng XH, Zhao XP, Yang DL: Expression of PTEN, PPM1A and P-Smad2 in hepatocellular carcinomas and adjacent liver tissues. World J Gastroenterol 2007, 13: $4554-4559$

75. Bu S, Kapanadze B, Hsu T, Trojanowska M: Opposite effects of dihydrosphingosine 1-phosphate and sphingosine 1-phosphate on transforming growth factor-beta/Smad signaling are mediated through the PTEN/PPM1A-dependent pathway. J Biol Chem 2008, 283: 19593-19602

76. Brautigan DL, Brown M, Grindrod S, Chinigo G, Kruszewski A, Lukasik SM, Bushweller JH, Horal M, Keller S, Tamura S, Heimark DB, Price J, Larner AN, Larner J: Allosteric activation of protein phosphatase $2 \mathrm{C}$ by D-chiro-inositol-galactosamine, a putative mediator mimetic of insulin action. Biochemistry 2005, 44: $11067-11073$

77. Malki K, Uher R, Paya-Cano J, Binder E, Rietschel M, Zobel A, Mors O, Hauser J, Henigsberg N, Jerman B, Souery D, Placentino A, Ng MY, Cohen-Woods S, Sluyter F, Farmer A, Aitchison KJ, Craig IW, Lewis CM, McGuffin P, Schalkwyk LC: Convergent animal and human evidence suggests a role of PPM1A gene in response to antidepressants. Biol Psychiatry 2012, 69:360-365 